\title{
Introduction of a Systemic Innovation Management Model for Facilitating Process Innovation
}

\author{
Dr. Marianne Schoorl \\ Noordwest Ziekenhuisgroep, Department of Clinical Chemistry, Haematology \& Immunology Alkmaar \\ Pieter Kievit \\ Westfries Gasthuis, Hoorn \\ Jeanette Oomes
}

Waterland Ziekenhuis, Department of Clinical Chemistry \& Haematology

Dr. Piet CM Bartels

Hogeschool Inholland, Alkmaar

\begin{abstract}
Within health care projects for change and innovation, professionals should ambitiously cooperate in order to yield a creative multidisciplinary mindset for guaranteed innovative output. Failure of innovation projects is amongst others due to deterioration and insufficient focus on relational aspects. Aim; an innovative management tool for facilitating process innovation is launched. Methods; Systemic innovation (SI) is a social network management model, subsidiary to actual management models for quality improvement and innovation. The SI management model yields essential tools for stimulation of communication in multidisciplinary teams in order to shape alternative mindsets. Results; The key domains of SI representing socio-dynamics, value of arguments and flexibility for change concern topics for assessment of behavior with regard to psychosocial and organizational characteristics. The key domains yield a format enabling a critical appraisal concerning improvement of socio-technologic aspects in case of process innovation. Conclusion; SI yields a format for stimulation of social awareness with regard to self-assessment, interoperability and mindset generation in multidisciplinary teams of professionals.
\end{abstract}

Keywords: communication, changeability, socio-technology, systemic innovation, quality management

\section{Introduction}

Quality and innovation management has evolved into a broad set of principles, methods and methodologies with a focus on organizations, culture and processes. Initially, quality assurance concerned technological issues in a production process which can be controlled. For assurance purposes tools and quality models focusing on process and product quality were generated. Characteristics of the so-called first generation of quality management systems include statistical process control, product inspection, process manuals (Jonker 2013).

Later on, the second generation of quality management models concerning the integral organization were implemented (1970-1990), including attention to contextual factors which influence processes and products. From this focus the EFQM

Model was generated, which is based on the integration of five key organizational domains and four key stakeholders domains. The EFQM Model revealed that hard core aspects and soft factors play a complementary role in the performance towards high levels of integral quality management in complex organizations.

From 2008 the so-called IMWR-cycle, an abbreviation of Inspiration, Mobilization, Appreciation and Reflection, has been added to the Dutch INK Management Model. With application of this feedback cycle the HRM aspects for changeability have been implemented in the technical and relational aspects of the operational management (Jonker 2013). Nowadays, it is clear that the input of human resources cannot be assured in this way and that an alternative approach is needed. 
Tools and procedures for solving problems between employees and within the context of mutual relationships are needed. Communication and interaction, support and intervention in culture aspects are considered to be key words for quality improvement and innovation.

Process innovations are considered to be key drivers for quality improvement of patient care, wellbeing and quality of life. However, in daily practice process innovation projects frequently exceed the previously established timeframe and project management fails to deliver on outcome targets. In our opinion, delay is amongst others due to insufficient focus on human relational aspects. Implementation of innovation projects and quality improvement systems in health care organizations is a rather complicated, tedious and time consuming challenge (Berwick 2003). With respect to process management and evaluation of innovation projects, an approved methodology to establish return on investment is not available (Brutscher 2008). A basic management model applicated for evaluation of strategy and monitoring of performance indicators for innovation is the added value chain model (Porter 1985). The management model just mentioned considers the strength of an integral chain of activities which are required to guide a product from the conceptual phase to several stages of manufacturing, delivery to consumers and final disposal. This third generation of quality management differs from the previous two generations in the sense that it has a perspective on the organization as an actor in the middle of a network of other organizational actors (Jonker 2013).

A review of literature references yields a wide range of change management models which have been applicated for quality improvement (Ten Have 2007, Bakker 2013, Cozijnsen 2003). The EFQM/INK Management model, the Balanced Score Card methodology and principles of LEAN and Six Sigma are frequently applicated in health care organizations because of the approved additional value with respect to ISO accreditation. These management tools are mainly applicated to manage on business performance indicators coupled with soft performance indicators for process improvement, quality assurance and innovation (Table I).

Table I: Fundamental issues of ISO 9001 and EFQM Business Excellence Model.

\begin{tabular}{|l|l|}
\hline ISO 9001 & EFQM Excellence Model \\
\hline Leadership & Leadership with Vision, Inspiration and Integrity \\
\hline Customer focus & Adding value for Customers \\
\hline Engagement of People & Succeeding through the Talent of People \\
\hline Relationship management Process approach Evidence & Developing organizational competences managing with agility \\
\hline Improvement & Harnessing Creativity and Innovation \\
\hline & Creating a sustainable future Sustaining outstanding results \\
\hline
\end{tabular}

For improvement of business performance an alternative mindset is needed for constructive interaction of professionals within a multidisciplinary team. Concerning innovation state of the art human resources management is considered to be a critical factor for success. In a multidisciplinary professional setting partners have to cooperate for exploration of a creative mindsetting. However, ready-to-use management models for systematic improvement by means of interventions in the area of behaviour, social infrastructure, business control and communication are not yet available (Bakker 2013).

\subsection{Application of a new management model for systemic innovation (SI)}

In view of the changing focus of quality system design, we recommend application of an integrated model for consultation and assessment of socio-emotive future perspectives in addition to actual state of the art management models. A strategy in order to demonstrate how sociotechnological principles can be applicated as a tool box for integrating process technology and HRM in order to perform a system of communication in action is demonstrated in Figure 1. Implementation of a management model for facilitation of innovation yields additional skills with regard to change capability and introduction of prerequisites for social network interaction between employees. Key performance indicators include individual competence of cooperation, exploration of creative power for professionals, application of individual talents and innovative knowledge exchange, pooling of multi-professional innovative expertise. Focussing on key performance indicators concerning socioemotive dimensions will encourage ambition and social interaction between professionals in case of innovation processes. 


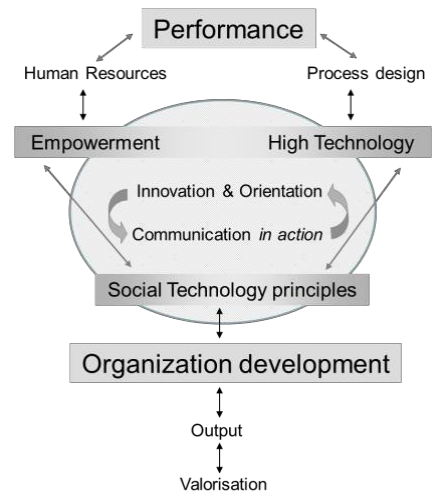

Figure 1: Example of a strategy in order to demonstrate how sociotechnology principles can be used as a tool for integrating process technology process and HRM in order to develop a system of communication in action and innovation. Organizational development with inclusion of sociotechnology results in a reliable strategy for valorisation of innovation output.

SI yields a format for coaching of the process of autopoiesis and interoperability in a team of professionals. When guided, autopoiesis and interoperability will yield intrinsic power and nourish relationships within members of a team. Empowerment facilitates individual performance and execution of processes based on constructive innovative ideas. With regard to assessment of team performance, a social network check list is considered to be an essential tool for feed back and exploration of relationships between subjects in a multiprofessional team (Figure 2).

\section{Methodology}

The social process concerning exchange of innovative ideas and subsequent action is indicated as interoperability which is mainly based upon communication. Interoperability and communication in action are complementary links within the chain of social interactions which are needed for successful performance of an innovation project. Within this respect the inter part of the word interoperability concerns improvement of relationships within and between several social systems and the operability part represents performance of processes on the basis of shared innovative ideas (Figure 2). Luhmanns social system theory yields cornerstones for construction of a theoretical framework with key performance indicators in order to assess, analyze and improve performance (Luhmann 1995). Within Luhmann's social system theory, the social process concerning communication in action includes a trias of terms including information, utterance and understanding (Figure 2). The process which generates inspiration and ambition within a team is indicated by the concept of mindset generation (Weick 1995). The concepts of exchange of information and inspiration by means of a common mindset generation have been merged in the model of interoperability (Van Lier 2009).

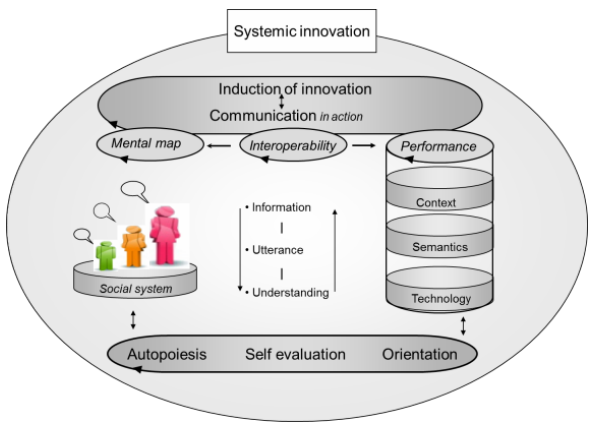

Figure 2: Systemic innovation yields a system for autopoiesis and interoperability in a multidisciplinary team of professionals. Autopoiesis and interoperability concern intrinsic power and relationships within teams and a performance structure for execution of processes based on shared innovative knowledge. 
The process of innovation requires understanding of specific interests of stakeholders and employees. Experience concerning sense of urgency and ability to interact is regarded as a stimulus for action (Kievit 2014). In the SI Management Model indicators for generating communication in action are defined. The key domains of SI representing sociodynamics, value of arguments and flexibility for change concern topics for assessment of behavior with regard to psychosocial and organizational characteristics (Table II).

Table II: Systemic innovation management model: indicators for generation and evaluation of communication in action.

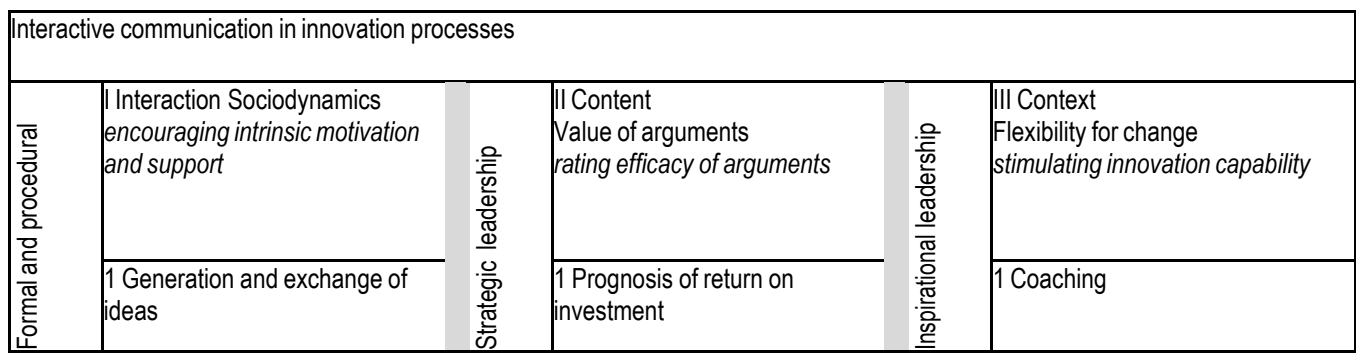

\begin{tabular}{|c|c|c|}
\hline $\begin{array}{l}2 \text { Creating consensus on the } \\
\text { basis of interaction }\end{array}$ & 2 Added value within the chain & 2 Ambition for experiments \\
\hline 3 Responsibilities and initiative & $\begin{array}{l}3 \text { Orientation about origin of } \\
\text { arguments }\end{array}$ & 3 Mental Map / Adaptibility \\
\hline $\begin{array}{l}4 \text { Competence and expertise } \\
\text { based on experience }\end{array}$ & 4 Decision making & 4 Learning organization \\
\hline
\end{tabular}

\section{Sociodynamics}

The process of sociodynamics is framed for assessment by application of critical performance indicators which yield a scope for self assessment. Indicators in the domain for sociodynamics reflect stimulation of intrinsic motivation and support. Examples are generation and exchange of ideas, creating consensus and ambition for amongst others taking responsibilities (Table II).

A process of communication and interaction is finished with a decision. The process for making decisions in a team is characteristic and is either achieved by expression of willingness (consensus) or by dominance of a team member. The way in which the role of leadership is fulfilled is essential in the process of decisionmaking.

\section{Value of argumentation}

Indicators in the domain of value of arguments reflect the efficacy of arguments applicated in the 'communication in action' process. Examples are added value, efficacy and the origin of arguments. (Table II).

Communication implicates statements reflecting context and event for embedding of an innovative idea. Statements regarding additional value are selected and supported upon an incentive within general commercial impact. Dynamic and constructive interaction between teams and between members within a team is of essential importance. The yield of inspiration and motivation by means of communication can be supported by perception of putative relationships with other individuals.

A social network configuration yields protection and prevents safety whereas it prevents chaos by application of communication. For optimal protection, critical assessment of investment regarding time, finances, creativity and energy is needed. Yield implicates assessment of the value of an incentive in a process of communication. Participation implicates a 
definite choice between undertaking an action for its own sake or for general purposes because of an expected return of investment.

Leadership facilitates a strategic context for using arguments within the process of decision making.

\section{Flexibility for change}

In an innovation oriented social network configuration communication in action is a functional tool for strengthening of the alignment from individual mindsets when formulating a concept of shared experiences of the past and challenges for the future. The domain for flexibility for change, implicates orientation and a potential scope for dynamic action. Indicators reflect the innovation capability of a team, in particular ambition for experimenting, culture and team development (learning organization). (Table II).

Authority of peers is an added value indicator because of the ability to reflect on past events and anticipate on future targets. Arguments are supported by a superior standard together with personal authority or by evoking values and practices for the future by way of trial and error. Inspirational leadership is of importance for implementation realisation of a learning organization concept.

\section{Perspectives}

\section{Sociodynamics}

The procedure for initiation and implementation of innovation projects primarily involves intervention in the field of hard core aspects, which refer to organization structure and management of processes. In case of monitoring proceedings of change management social aspects of interaction should receive particular attention. Within this respect, the checklist of the SI management model will yield additional value in high tech organizations like hospitals. Mostly, a strategy oriented change model implicates a top down intervention strategy with a predefined concept for a management program. In particular, it is difficult to manage implementation of a process based innovation project, because the context of co-creation and cooperation does not only regard to individual employees but it also implicates flexibility and changeability of a multiprofessional team, department or organization.

\section{Learning organization}

A development oriented change strategy includes creativity and interventions which are performed in a participative management style. Changes are performed more conveniently by focusing on management issues concerning "soft" organizational aspects like behaviour, culture and mode of interaction between employees. Application of the SI management model for culture intervention is focused on the generation of a learning environment which inspires employees in gaining knowledge and innovative insights. Commitment is mainly performed based on a bottom up approach. It is recommended to stimulate participation of employees and to establish in advance which specific targets should be achieved.

Ambition and highly motivated staff for involvement within innovation projects is needed to get employees engaged in innovation and organization development. Facilitation of engagement implicates adoption and promotion of innovations. Rules and attitudes within a system emerge from members' experiences and the feelings of sensemaking. (Greenfield 2011). Within the process of interaction creativity and surprise are practiced as an educational factor in order to increase awareness.

A system of personal assessment evolves exploration of individual talents. Social networks of innovative knowledge are going to be explored in response to challenge and opportunity, technology, social and political change. In due time application of an innovative system for multiplication of talent yields an exponential increase in creative capacity and flexibility (Cheese 2008). It is a challenge to utilize human energy dynamics for realization of new ideas thus creating additional power and trust for innovation projects.

Engaged employees exhibit a high level of energy, ambition and emotional investment in a job because it is considered to be meaningful for both the organization and for themselves. Information and knowledge expert systems are difficult to explore and subsequently to share with other teams. Talent multiplication should be considered as a strategic issue and an integral component of business challenge strategy. The strategy for talent exploration is based on a pervasive talent 
mindset and an organization culture driven by leadership. Top down understanding in case of a human capital strategy is required to support high tech oriented business strategy and exploration of added value linkages (Cheese 2008). Education programs should explore strategic targets with respect to social and emotional topics. Innovative expertise domains need also to be introduced and discussed in education programs. Competences include a set of individual skills, knowledge and behavior in order to fulfill a job effectively. Skills implicate what an individual is able to do, development is based on learning and experience. Behavior and attitude refers to how an employee should act to be effective. Behavior incorporates both emotional and social components. Social components include individual characteristics like self awareness, confidence, trust and willingness to collaborate. Business performance is achieved by construction of an additional competency framework (Cheese 2008).

\section{Strategy for implementation}

Creative ideas need nourishment for exploration. Inspiring leadership is a key issue in case of inventarisation of essential requirements for an innovation strategy. $\mathrm{SI}$ is applicated by means of individual coaching and brainstorming sessions. As mentioned before, application of SI implicates a focus on shared values rather than on opposite forces of attraction and rejection between individuals. We recommend application of a set of performance indicators regarding the SI management model in addition to the state of the art management models, such as ISO9001 or EFQM. Performance indicators are assessed within a scope of several dimensions (Table III).

Table III: Characteristics of the EFQM excellence Model and the Systemic Innovation Management Model

\begin{tabular}{|l|l|l|}
\hline Characteristics & EFQM Excellence Model & Systemic Innovation Model \\
\hline Perspective on quality & Holistic & Multifocus \\
\hline Focus & Synergy & Change \\
\hline \hline Type of action & proactive & Selfdefinition \\
\hline Criteria for succes & Efficiency \& efficay & Innovation \\
\hline Orientation & Processes & Interaction \\
\hline Change & Challenge & Mindset \\
\hline Characteristics of engagement & Negotiate (and/or) community involvement & Values \\
\hline Conceptual character & & \\
\hline
\end{tabular}

Interoperability as the driving force

Additional care for efficacy of cross junctions between several strategic pathways for involvement of employees is needed for appropriate exchange of information. The so-called communication in action generating process is also indicated as a method to yield interoperability of information. A systematic approach for innovative knowledge transfer combined with action oriented communication is recommended as a management target rather than being left to chance by application of a laisser faire strategy.

During the implementation stage of an innovation process alternative insights will develop.

\section{Performance}

A paradigma-shift is established in management models for business design. Culture intervention including systematic knowledge development implicates establishment of key performance indicators and analysis of results, identification of critical processes and training staff. Ongoing management efforts with regard to innovation capacity in social competences should be performed by a skilled staff working together within a multidisciplinary team coached with inspirational leadership. Individual employees as well as teams play a key role in realization of synergy in case of process innovation. Transformation processes are characterized by creation of additional value and exchange of innovative expertise. Delay in decision making procedures is a rather complicated phenomenon because of the high amount of professional functions and interfaces on the road map for communication. In cultural anthropology patterns of human behavior, mindsetting and individual feelings are considered as main topics in case of transformation processes. The human factor is a relevant issue for stimulation of wellbeing and planning intervention of culture. Within this respect, communication in action is considered to be an essential factor in projects for innovation (Haviland 2011). In the field of scientific studies concerning communication, relevant dimensions for management improvement are considered to be transfer of message, language, objectivity in understanding 
and interpretation of information regarding context, sociology and expression of ideas, and feelings for better perception and understanding.

\section{Systemic Innovation in a Nutshell}

$\mathrm{SI}$ is recommended as an innovative tool for stimulation of interoperability in case of process innovation. The SI management tool reveals a checklist for stimulation of interaction within a social network. It yields criteria for evaluation of interactive communication in order to generate a creative mindset and to yield innovative output within a multidisciplinary setting. Particular focus on communication in addition to actual management models will facilitate action by cross talks on the level of innumerable junctions within the matrix for communication within an organization. Cross talks enable release of energy, compassion and ambition for innovation.

\section{References}

[1] Bakker R.M., Hardjono T.W. (2013). Horizontaal organiseren - Horizontaal en procesgericht denken, construeren, besturen en samenwerken. Vakmedianet: Alphen aan den Rijn.

[2] Berwick D.M. (2003). Disseminating Innovations in Health Care. JAMA, 289,1969-1975.

[3] Brutscher P.B., Wooding S., Grant J. (2008). Health Research Evaluation Frameworks: An International Comparison. [Online

[4] Cheese P., Thomas R.J., Craig E. (2008). The talent powered organization. Kogan Page, London.

[5] Cozijnsen A., Vrakking W. (2003). Handboek verandermanagement - Theorieën en strategieën voor organisatieverandering. Vakmedianet, Alphen aan den Rijn.

[6] Greenfield D., Pawsey M., Braithwaite J. (2011). What motivates professionals to engage in the accreditation of healthcare organizations? Int J Qual Health Care, 23,8-14.

[7] Haviland J.B. (2011). Musical spaces. In: Multimodality and human activity: Research on human behavior, action, and communication. Cambridge University Press Cambridge \& New York, pp 289-304.

[8] Jonker J., Reichling A. (2013). Derde generatie kwaliteitsmanagement. Over organisaties en organiseren en veranderingen in het denken over kwaliteit. In: Derde generatie kwaliteitsmanagement. Vakmedianet, Rotterdam.

[9] Kievit P., Oomes J., Schoorl M., Bartels P.C.M. (2014). Talking about Innovation in Health Care... J Systems Science, 3,1-11.

[10] Luhmann N. (1995). Social Systems. Stanford University Press, Stanford.

[11] Porter M.E. (1985): Competitive Advantage: Creating and Sustaining superior Performance. Free Press, New York.

[12] Ten Have S. (2007). Het Managementmodellenboek van Berenschot. Elsevier, Amsterdam.

[13] Van Lier A.F. (2009). Luhmann meets 'the Matrix': Exchange and sharing of information in net-centric environments. Thesis. Eburon, Delft.

[14] Weick K.E. (1995). Sensemaking in organizations. Sage publications, Thousand Oaks 